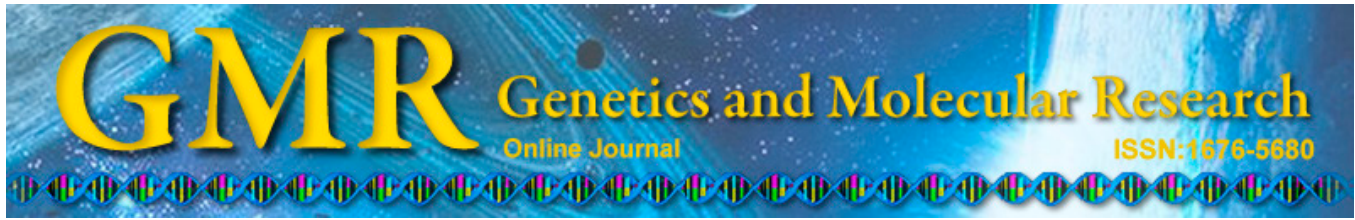

\title{
Transthoracic closure of atrial septal defect and ventricular septal defect without cardiopulmonary bypass
}

L. Wan, B.-T. Yu, Q.-C. Wu, L. Zeng, Q. Wang, J. Tang, Q.-R. Xu, H. Xu, W.-J. Wang, Y.-P. Cao and J.-C. Liu

Department of Cardiothoracic Surgery, First Affiliated Hospital of Nanchang University, Nanchang, Jiangxi Province, China

Corresponding author: J.-C. Liu

E-mail: jichunliucn@163.com

Genet. Mol. Res. 14 (2): 3760-3766 (2015)

Received May 5, 2014

Accepted October 7, 2014

Published April 22, 2015

DOI http://dx.doi.org/10.4238/2015.April.22.4

ABSTRACT. The minimally invasive surgical transthoracic occlusion
of an atrial septal defect (ASD) or a ventricular septal defect (VSD) is
an increasingly widespread alternative treatment for congenital heart
disease. The aim of this study is to summarize our clinical experience
with minimally invasive surgical transthoracic occlusion of ASD and
VSD without cardiopulmonary bypass (CPB). Between April 2011 and
October 2012,27 patients with ASD and 95 patients with VSD ( 78
men and 44 women) were considered for minimally invasive surgical
transthoracic occlusion without CPB. A small infrasternal incision (2.0-
$4.0 \mathrm{~cm}$ ) was made under general anesthesia, under transesophageal
echocardiography (TEE) guidance; the ASD and VSD were closed by
using an appropriate occluder; and TEE was performed simultaneously
to demonstrate the position of the device, any residual shunting, or
encroachment on the atrioventricular valve, coronary sinus, or aortic
valve. Successful transthoracic occlusion was performed in all 122 
patients without complications. No complications such as thirddegree atrioventricular block and residual shunting occurred after the procedures. The ventilation time was $2.2 \pm 1.2 \mathrm{~h}$, and the average length of hospital stay was $4.7 \pm 1.7$ days. All patients received aspirin at $3 \mathrm{mg} \cdot \mathrm{kg}^{-1} \cdot$ day $^{-1}$ (maximum $100 \mathrm{mg} /$ day) $24 \mathrm{~h}$ after the procedure. Minimally invasive surgical transthoracic occlusion without CPB is a new treatment that has many advantages such as causing little trauma, promoting quick recovery, having less complications, and avoiding radiation damage. However, the appropriate selection of patients is still key to improving the success rate of the operation.

Key words: Atrial septal defect; Ventricular septal defect; Surgery; Transthoracic occlusion

\section{INTRODUCTION}

Congenital heart diseases (CHDs) such as atrial septal defect (ASD) and ventricular septal defect (VSD) are the most common birth defects in humans. The traditional treatment for CHDs is open heart surgery through cardiopulmonary bypass (CPB), which is a mature and effective method but has disadvantages such as causing great trauma to the patient and a long hospital stay. Transcatheter occlusion is another treatment method (Fischer et al., 1999; Berger et al., 2001; Li et al., 2012; Kazmouz et al., 2013; Vasquez and Lasala, 2013). However, its shortcomings include peripheral vascular injury, radiation damage, and a high incidence of complications; fewer indications and high cost; and an unexpected status that is difficult to control. In recent years, as a hybrid technique (Hjortdal et al., 2002), minimally invasive surgical transthoracic occlusion of CHD without CPB has shown satisfactory outcomes. In this article, we report our experiences with 122 consecutive cases of simple CHD treated with minimally invasive surgical transthoracic occlusion without $\mathrm{CPB}$ in our hospital between April 2011 and October 2012.

\section{MATERIAL AND METHODS}

\section{Subjects}

Between April 2011 and October 2012, 27 patients (16 men and 11 women) were found to have ASD and 95 patients ( 62 men and 33 women) were found to have VSD. Their ages ranged from 6 months to 69 years (mean, $15 \pm 3.1$ years). Their body weight ranged from 5 to $59 \mathrm{~kg}$ (mean, $25.0 \pm 9.6 \mathrm{~kg}$ ). All patients had respiratory infection before the operation. Pulmonary congestion and different degrees of heart enlargement were seen on chest radiographs. All ASD patients showed secundum ASDs on transesophageal echocardiography (TEE); the defect diameter varied between 6.0 and $32.0 \mathrm{~mm}$. Among patients with ASD, 17 had mild pulmonary hypertension, 9 had moderate pulmonary hypertension, and 1 had severe pulmonary hypertension. The 95 VSD patients showed a membranous defect $(\mathrm{N}=83)$, subarterial defect $(\mathrm{N}=9)$, and muscular defect $(\mathrm{N}=3)$, with the defect diameter ranging from 3.0 to $8.0 \mathrm{~mm}$; also, 45 patients had mild pulmonary hypertension, 47 had moderate pulmonary hypertension, and 3 had severe pulmonary hypertension. All patients showed normal function 
of the heart valve and had no other heart malformations. This study was conducted in accordance with the Declaration of Helsinki and with approval from the Ethics Committee of the First Affiliated Hospital of Nanchang University. Written informed consent was obtained from all participants.

\section{ASD procedure}

TEE was performed with the patient under general anesthesia to evaluate the size and location of the defect and its distance from the superior and inferior cava, aortic wall, pulmonary vein, coronary sinus, and mitral ring. The patients were placed in the supine position; a 2.0-4.0-cm infrasternal incision was made, separating the back of the Xiphoid process; the tissue below the sternum was dissociated; the sternum was partly sawed; and the pericardium was opened and suspended to expose the heart. TEE was performed to confirm the size and location of the defect and its relationship with the surrounding valve. An appropriate occluder was selected, the diameter of which was ideally 2.0-4.0 mm larger than the defect. Heparin sodium $(1 \mathrm{mg} / \mathrm{kg})$ was administered to maintain the whole blood activated coagulation time $(\mathrm{ACT})$ at $>250 \mathrm{~s}$. A purse-string suture was sewn at the site of the right atrium outer wall. The delivery sheath was punctured into the right atrium through the center of the suture and then into the left atrium through the defect, under TEE surveillance. The chosen occluder (Shanghai Shape Memory Alloy Material Co., Ltd., Shanghai, China) of the right size was delivered by using the sheath through the defect and was then released. Under electrocardiography and TEE surveillance, the "push-pull" test was performed to adjust the position of the occluder release and to ensure that the waist of the occluder would straddle the edges of the defects firmly and well. There were no residual shunts, atrioventricular and semilunar valve influences, thirddegree atrioventricular blocks, or other complications. Thereafter, the delivery sheath was pulled out of the heart, and the double purse-string was ligated tightly; electric coagulation hemostasis of the pericardium was performed; heparin was neutralized with protamine at a 1:1 ratio; a pericardium drainage tube was inserted; and the thoracic incision was closed layer by layer. The average operation time was $39 \pm 11 \mathrm{~min}$, and the time of operating on the heart was $10 \pm 6 \mathrm{~min}$. An aspirin tablet (3-5 mg/kg) was administered for anticoagulation, orally once a day for 3 months, and intravenous antibiotics were given for 3 days to prevent infection.

\section{VSD procedure}

The patients were given general anesthesia through nasal tracheal intubation. An esophageal ultrasonic probe was placed into the patients' esophagus through the mouth. Patients were placed in the supine position; an incision was made at the center of the sternum, 2.0-4.0 cm in length; and the substernal segment was split with an electric saw. After pericardial incision and application of a sling to the chest wall, the right ventricle was exposed, and heparin $(1 \mathrm{mg} / \mathrm{kg})$ was administered through intravenous injection. When the ACT surpassed $250 \mathrm{~s}$, the position and size of the VSD and its relation to the valve were confirmed by TEE (Figure 1A), and a double purse-string suture was sewn at the site of the vessel-free region of the right ventricle. The delivery sheath was punctured into the right ventricle through the center of the suture, and then into the left ventricle through the defect under TEE surveillance (Figure 1B). The chosen occluder (Shanghai Shape Memory Alloy Material Co., Ltd.) of the right size was delivered by using the sheath through the defect and was then released (Figure 
1C). Under electrocardiography and TEE surveillance, the "push-pull" test was performed to adjust the position of the occluder release and to ensure that the waist of the occluder would straddle the edges of the defects firmly and well (Figure 1D). There were no residual shunts or other structure influences. The delivery sheath was then pulled out of the heart, and the double purse-string was ligated tightly. It is advisable to choose an occluder that has a diameter that is $1.0-2.0 \mathrm{~mm}$ larger than the defect. Electric coagulation hemostasis of the pericardium was performed; heparin was neutralized with protamine at a 1:1 ratio; a pericardium drainage tube was inserted; and the thoracic incision was closed layer by layer. The average operation time was $63 \pm 22 \mathrm{~min}$, and the time of operating on the heart was $22 \pm 9 \mathrm{~min}$. An aspirin tablet (3-5 $\mathrm{mg} / \mathrm{kg}$ ) was administered for anticoagulation, orally once a day for 3 months, and intravenous antibiotics were given for 3 days to prevent infection.

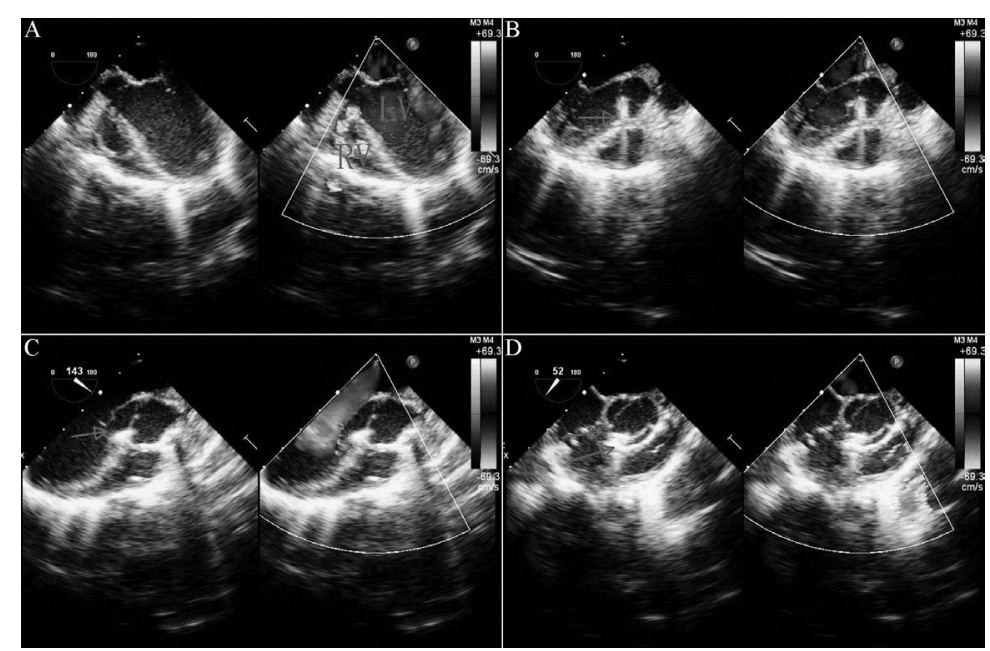

Figure 1. Echocardiogram of closure of VSD. A. Echocardiogram before operation; B. the sheath delivered from right ventricle to left ventricle via VSD; C. occluder released on left ventricle side; D. occluder released on right ventricle side.

\section{RESULTS}

The operation was performed successfully in all patients. Two patients received intraoperative blood ( $0.5 \mathrm{U}$ ) transfusion because of preoperative anemia; none of the other patients received blood transfusion. After the operation, the patients stayed in the intensive care unit for 6-24 $\mathrm{h}$ and were thereafter transferred to the general ward. The ventilation time was $2.2 \pm$ $1.2 \mathrm{~h}$ (range, 0.5-6 h), and the average length of hospital stay was $4.7 \pm 1.7$ days (range, 3-7 days). Heart murmur disappeared postoperatively. Transthoracic echocardiography showed that the occluder adapted to the movement of the atrial and ventricular septum very well, and there were no obvious complications such as occluder dropping, residual shunt, or thrombopoiesis. No complications occurred after 3-22 months of follow-up.

\section{DISCUSSION}

ASD and VSD are the most common CHDs. At present, several operation methods 
are available, such as traditional median sternotomy repair of the defect with $\mathrm{CPB}$, repair of the defect with the heart beating (Yang et al., 2003), and small-incision repair of the defect (Massetti et al., 1996). Although these methods result in improved myocardial preservation and incision healing, they still require extracorporeal circulation and cannot be considered minimally invasive surgeries. The transcatheter approach eliminates the trauma of CPB and has advantages such as producing small wounds, quicker recovery, less pain, shorter hospital stay, and a high cure rate. However, with this approach, the conveyor passes through many important structures of heart over a long distance, potentially causing vascular injury (Xing et al., 2011; Zhang et al., 2013) and leakage. Moreover, it is harmful for patients and surgeons to be exposed to X-rays for a long time, especially children (Hu et al., 2009). Some instances of failure and complications such as cardiac perforation and dropping of the occluder have also been reported, on using the transcatheter approach. Residual shunt has been reported to occur in $15-30 \%$ of the patients (Zhu et al., 2009) after a transcatheter procedure, as well as a higher incidence of atrial fibrillation (Giamberti et al., 2006). The percutaneous approach is not suitable for infant surgery because it is difficult to insert the delivery sheath into an infant's small femoral vein. Meanwhile, the fewer indications and high cost of the transcatheter approach limit its clinical application.

Transthoracic small incision occlusion is one of the newest treatment methods for ASD and VSD. In 1998, Amin et al. first reported that it is feasible to successfully deploy an Amplatzer occluder for membranous and muscular VSDs in an animal model. In 2003, in a children's hospital in Chicago, Bacha et al. reported on 6 children with muscular VSD who were successfully treated with transthoracic occlusion. Since then, many other articles have been published about the successful application of an Amplatzer occluder for muscular VSD using the transthoracic approach (Amin et al., 1998; Bacha et al., 2003; Cao et al., 2011; Zhang et al., 2012). In 2004, Amin et al. achieved satisfactory outcomes by using a transthoracic approach for treating membranous VSD in an animal model.

In our study, minimally invasive occlusion was shown to be a new treatment using the transcatheter approach and traditional surgery, with the following advantages. First, it requires a small chest incision with excellent cosmetic outcomes, without the use of $\mathrm{CPB}$, allowing fast recovery. Second, only TEE monitoring is required, without the use of X-rays and contrast agents. Three, it has wider indications. The umbrella device is hard enough to support the rim of the defect, so it is safer to apply our approach to several special defects for which the intervention is difficult, such as large ASDs (diameter $>30 \mathrm{~mm}$ ) or partial edge deficient ASDs. We used an eccentric occluder for subarterial VSD whose distance from the aortic valve was $<2.0 \mathrm{~mm}$ (even no distance) and achieved good results without aortic regurgitation. A small incision was created on the chest, and the procedure was not limited by the diameter of femoral vein; therefore, the approach could be used in infants. Meanwhile, complications such as cardiac tamponade, iatrogenic pseudoaneurysm, and arteriovenous fistula could also be avoided (Kang et al., 2000). Fourth, the defect was facing the delivery sheath and was parallel to the umbrella device; therefore, the approach was fast and convenient, with several additional advantages such as applicability, maneuverability, and flexibility. Fifth, the "push-pull" test was performed to check whether the umbrella device was sufficiently firm. Complications such as occluder dropping and residual shunt seldom occurred because the appropriate occluder was chosen and its position could be adjusted promptly. Further, it is convenient to convert to a CPB operation in case of emergency events. Sixth, the approach is inexpensive (Pedra et al., 2000).

To improve the success rate of the transthoracic approach, we found that the follow- 
ing points should be given attention. First, the procedure should be administered under TEE surveillance synchronously, and the sonographer should have good clinical experience and knowledge of the heart anatomy. Second, the cases must be selected carefully preoperatively; patients who simultaneously have other heart diseases such as aortic valve prolapse with moderate to severe regurgitation and infective endocarditis should be operated normally with CPB. The atrioventricular channel type and malalignment type of VSDs are not suitable for occlusion. The VSD diameter should ideally be $>3 \mathrm{~mm}$ and $<8 \mathrm{~mm}$, and the patient should be older than 3 months. Third, the surgeon should have proficient operative skills and should be able to perform open heart surgery if occlusion fails. Fourth, patients should receive anticoagulation therapy for 3-6 months to prevent thrombosis and steroid treatment for 3 days to prevent conduction block due to tissue edema. Fifth, long-term follow-up is recommended to detect complications such as gas embolism, occluder dropping, valve malfunction, conduction block, and obstruction of vena cava reflux.

In conclusion, compared with the open heart surgery with CPB and transcatheter intervention therapy, minimally invasive transthoracic occlusion of the defect without $\mathrm{CPB}$ is a novel and effective treatment, with advantages such little trauma, good maneuverability, accurate positioning, better safety, wider indications, and fewer complications. The procedure is feasible and inexpensive owing to the use of a domestic delivery sheath and umbrella device, the use of which should be promoted. We are accumulating more clinical experiences of cases to confirm long-term outcomes.

\section{REFERENCES}

Amin Z, Berry JM, Foker JE, Rocchini AP, et al. (1998). Intraoperative closure of muscular ventricular septal defect in a canine model and application of the technique in a baby. J. Thorac. Cardiovasc. Surg. 115: 1374-1376.

Amin Z, Danford DA, Lof J, Duncan KF, et al. (2004). Intraoperative device closure of perimembranous ventricular septal defects without cardiopulmonary bypass: preliminary results with the perventricular technique. J. Thorac. Cardiovasc. Surg. 127: 234-241.

Bacha EA, Cao QL, Starr JP, Waight D, et al. (2003). Perventricular device closure of muscular ventricular septal defects on the beating heart: technique and results. J. Thorac. Cardiovasc. Surg. 126: 1718-1723.

Berger F, Ewen P, Abdul-Khaliq H, Nürnberg JH, et al. (2001). Percutaneous closure of large atrial septal defects with the Amplatzer Septal Occluder: technical overkill or recommendable alternative treatment? J. Interv. Cardiol. 14: 63-67.

Cao H, Chen Q, Zhang GC, Chen LW, et al. (2011). Intraoperative device closure of perimembranous ventricular septal defects in the young children under transthoracic echocardiographic guidance; initial experience. J. Cardiothorac. Surg. 6: 166.

Fischer G, Kramer HH, Stieh J, Harding P, et al. (1999). Transcatheter closure of secundum atrial septal defects with new self-centering Amplatzer Septal Occluder. Eur. Heart J. 20: 541-549.

Giamberti A, Chessa M, Foresti S, Abella R, et al. (2006). Combined atrial septal defect surgical closure and irrigated radio frequency ablation in adult patients. Ann. Thorac. Surg. 82: 1327-1331.

Hjortdal VE, Redington AN, de Leval MR and Tsang VT (2002). Hybrid approaches to complex congenital cardiac surgery. Eur. J. Cardiothorac. Surg. 22: 885-890.

Hu SS, Li DY, Yan J, Li SJ, et al. (2009). Hybrid treatment for younger and low weight atrial septum defect patients. $J$. Chin. Cardiovasc. Surg. 25: 96-98.

Kang YF, Cai ZJ and Cheng YG (2000). Video assisted thoracoscopic cardiac surgery in closure of atrial septal defect without extracorporeal circulation. J. Fouah. Milit. Med. Univ. 21: S197.

Kazmouz S, Kenny D, Cao QL, Kavinsky CJ, et al. (2013). Transcatheter closure of secundum atrial septal defects. J. Invasive Cardiol. 25: 257-264.

Li JJ, Zhang ZW, Qian MY, Wang SS, et al. (2012). Transcatheter interventional therapy of congenital heart disease: the results of Chinese TIT registry. Zhonghua Xin Xue Guan Bing Za Zhi 40: 283-288.

Massetti M, Babatasi G, Rossi A, Neri E, et al. (1996). Operation for atrial septal defect through a right anterolateral thoracotomy: current outcome. Ann. Thorac. Surg. 62: 1100-1103. 
Pedra CA, Pihkala J, Lee KJ, Boutin C, et al. (2000). Transcatheter closure of atrial septal defects using the Cardio-Seal implant. Heart 84: 320-326.

Vasquez AF and Lasala JM (2013). Atrial septal defect closure. Cardiol. Clin. 31: 385-400.

Xing Q, Wu Q, Pan S, Ren Y, et al. (2011). Transthoracic device closure of ventricular septal defects without cardiopulmonary bypass: experience in infants weighting less than 8 kg. Eur. J. Cardiothorac. Surg. 40: 591-597.

Yang X, Wang D and Wu Q (2003). Repair of partial atrioventricular septal defect through a minimal right vertical infraaxillary thoracotomy. J. Card. Surg. 18: 262-264.

Zhang GC, Chen Q, Chen LW, Cao H, et al. (2012). Transthoracic echocardiographic guidance of minimally invasive perventricular device closure of perimembranous ventricular septal defect without cardiopulmonary bypass: initial experience. Eur. Heart J. Cardiovasc. Imaging. 13: 739-744.

Zhang GC, Chen Q, Cao H, Chen LW, et al. (2013). Minimally invasive perventricular device closure of ventricular septal defect in infants under transthoracic echocardiographic guidance: feasibility and comparison with transesophageal echocardiography. Cardiovasc. Ultrasound 11: 8.

Zhu XM, Liu ZP, Zhao L, Wang J, et al. (2009). 41-case reports of transthoracic occlusion of atrial septum defect. J. China Min. Invas. Surg. 2: 141-142. 